\title{
The Neuro-Subject: A Living Entity with Learnability
}

\author{
Ángel Fidalgo-Blanco ${ }^{1}\left(\mathbb{D}\right.$, María Luisa Sein-Echaluce ${ }^{2(\bowtie)}(\mathbb{C})$ \\ and Francisco José García-Peñalvo ${ }^{3}$ (1) \\ ${ }^{1}$ LITI Laboratory, Technical University of Madrid, Madrid, Spain \\ angel.fidalgo@upm.es \\ 2 Department of Applied Mathematics, University of Zaragoza, Saragossa, Spain \\ mlsein@unizar.es \\ ${ }^{3}$ GRIAL Research Group, University of Salamanca, Salamanca, Spain \\ fgarcia@usal.es
}

\begin{abstract}
In the context of an academic subject, students and teachers acquire knowledge and experience, but we must ensure that this experience will be shared and managed. In this way, the learning, acquired in the subject, remains in the subject. A proven way to manage the experience, which has been validated in previous works, is based on considering two dimensions: the conversion of individual knowledge into organizational and the use of a knowledge management system that allows classifying, organizing and finding knowledge based on ontologies and inferences between them. The primary objective of this research work is to join the two dimensions and apply an active method to manage the experience acquired by the teaching staff and students. The combination of the models RT-CICLO, as an active method, and ACCI 3.0 to transform individual and organizational knowledge can be applied so that organizational knowledge and learning are produced in a subject. In this work we have identified the actions in which the students create knowledge, as well as the type of knowledge that is created in each case. Organizational knowledge can be generated from each action, which can also be used to promote individual student learning. In the experience also have been acquired a high perception of usefulness on the part of students with regard to all types of organizational knowledge created.
\end{abstract}

Keywords: Active methodologies $\cdot$ Collaborative learning $\cdot$

Knowledge spiral $\cdot$ Knowledge management system

\section{Introduction}

In the industry, mainly Japanese, the fact that learning takes place through the interaction of workers has been studied, and that learning must be saved and managed within the organization to improve it $[1,2]$. But for the learning to take place in the organization, it is necessary a set of phases of interaction between the implicit knowledge of a person (e.g., their experience) and explicit knowledge (e.g., a technical report that they have made). So, there is a knowledge spiral, called, epistemological spiral [2] that is based on the following phases: 
- Acquisition of knowledge, it can come from two types of interaction:

- Exchanging implicit knowledge of several people through socialization between them. This phase is called Socialization.

- Acquisitioning knowledge from the existing implicit knowledge. It is the phase called Internalization.

- Externalization of knowledge. In this phase the person who has acquired knowledge must externalize it. Thus, the person should not keep it, he should transfer it through external support that can be distributed within the organization, even in the absence of that person. This phase is called Externalization.

- Combination of explicit knowledge. When there is sufficient explicit knowledge in the organization, mainly produced by its members, it can be combined to produce new knowledge. To get this combination, it's necessary to identify, classify and facilitate the transfer of knowledge wherever it is needed. This phase is called Combination.

On the other hand, in the traditional academic teaching, the two main actors are the students and the teachers. The learning that occurs in the subject traditionally affects the students, but also in the teaching staff, since as they work on the subject increases their academic and teaching experience.

Thus, students and teachers learn through the acquisition of knowledge, skills and abilities. If the faculty continues to teach their subject, the experience gained impacts it, improving it. However, when students finish the course, this does not affect the learning acquired in the same since they leave.

In the context of an academic subject, the students and teachers acquire knowledge and experience, but you have to get this experience is shared and managed. The most suitable methodologies for the students to participate, cooperate and share are the active methodologies [3-7].

Numerous authors emphasize that active methodologies produce greater learning in students [8]. Authors, considered as historical, indicate that students learn more "doing" than "listening" [9, 10], the learning must begin with the active participation of the students and, also, this active participation must be doing continually [6]. Some characteristics of the active participation of students are action-reflection [11], cooperation [12], work with real problems [13], decision-making [11], and the creation of knowledge [14].

Likewise, it has been shown that the creation of knowledge itself requires high cognitive abilities on the part of the author, so their level of learning is higher than if they did not create knowledge [3]. On the other hand, the creation of knowledge by students can have different levels of certainty. For this reason, the feedback provided by the teachers to the students who create the knowledge is a key factor for learning occurs in the students, and this feedback should be as immediate as possible after the creation of that knowledge [15].

The main objective of this work is to apply the concept of organizational learning to academic subjects of the university context. For this, the student is considered a member of the organization that can learn and create. For the part of the organization must improve the learning of its members and, for this; it should promote the creation 
of individual and group knowledge, as well as the management of the same, so that impact both the organization and the own individual.

To get this main objective, it must be met these four objectives:

- Having a conceptual model that considers a subject as an organization that learns.

- Identifying the actions of the students that together with the actions of teachers can produce organizational knowledge.

- Identifying the types of organizational knowledge produced.

- Studying the perceptions of students on the utility for your learning of the different types of organizational knowledge.

The following sections will present the theoretical model on which this proposal is based, the research context that includes the measurement tools, as well as the results obtained, to end with the conclusions.

\section{Theoretical Model}

The initial theoretical model is based on the model proposed by Nonaka for an organization to carry out learning, this is called epistemological spiral [2]. The first step is based on correlating the different phases of this spiral with a traditional educational model. In this way, the feasibility of applying the model and the actions it carries can be analyzed.

The equivalence between the phases of the epistemological spiral and an educational model are those:

- Socialization. During the face to face classes, socialization takes place due to the interaction between the teachers and the students. This type of socialization can be weak (the lecturer holds a master class and the student is passive person) or strong (students and teachers participate in the class actively).

- Internalization. It occurs when the students study the notes that have taken personally during the lecture or with another teaching resource provided by the faculty, like notes or recommended books.

- Externalization. This phase is unusual among students because traditional methods don't promote the active participation of students, and don't generate teaching resources. In spite of that, there are numerous authors who point out the convenience of the students to create knowledge, as a method to improve their own learning. For example, the elaboration of notes by the students during the master class is an explicit sample of knowledge.

- Combination. During this phase the students does a specific academic activity individually. They usually combine explicit knowledge from different sources: their own knowledge, the knowledge of other classmates and that of the teaching staff. For example, in an exam they use the notes that they themselves have taken (explicit since they have generated it themselves), but they will also use notes of other classmates and those of the teaching staff.

From this relationship you can design the characteristics that the model must have in order to allow the subject "learn", that is, to increase organizational knowledge. 
Figure 1 shows those characteristics that are described below. The socialization phase is very common in educational models. Socialization is weak if the methodology used is passive on the part of the students (for example, a master lesson) and is strong if it is based on an active methodology where the students participate actively in their learning process. Therefore, a first requirement to apply this model is that the methodology must be active (Fig. 1a).

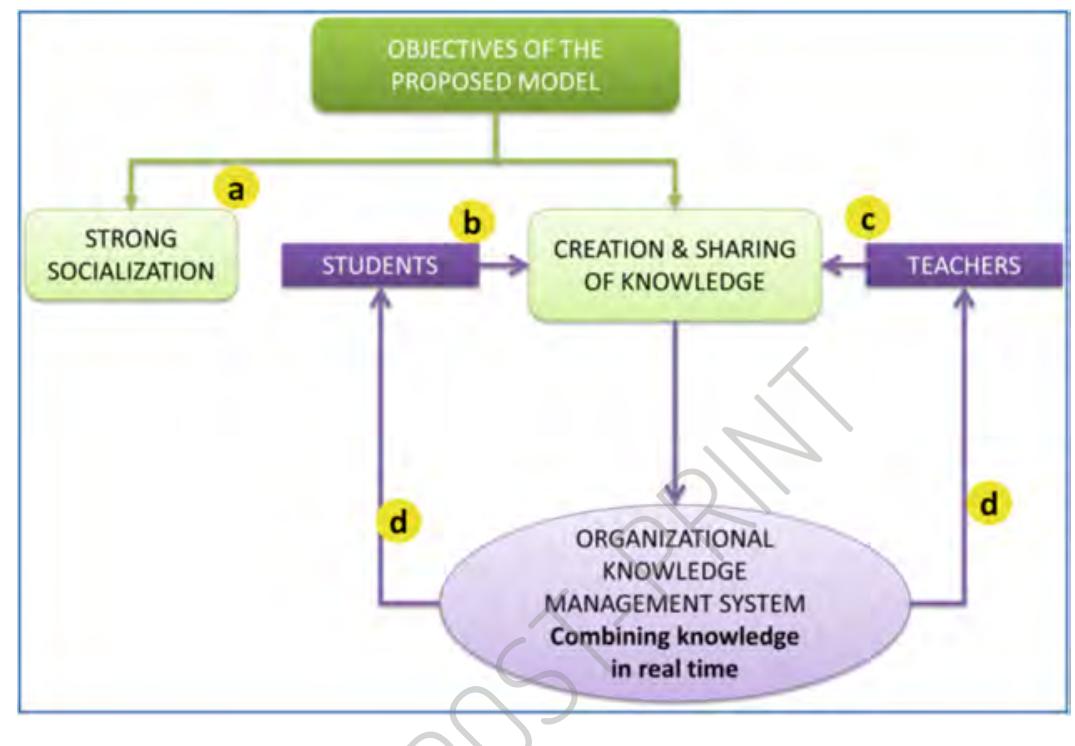

Fig. 1. Characteristics of the proposed model

The internalization phase usually occurs in the students, because they usually perform academic activities, such as preparing an exam, through explicit knowledge.

In the externalization phase it looks that both students and teachers transform tacit knowledge into implicit knowledge. In order to create organizational learning to occur, the members of the organization must externalize and share their knowledge. Therefore, the model used should motivate students and teachers to make explicit and share their experience. See Fig. $1 \mathrm{~b}$ and $\mathrm{c}$.

The combination phase is essential to do organizational learning. It is based on combining the experience of the students, which they previously shared, with the experience of the teaching staff. For that, we must be a tool that allows this combination of knowledge to be carried out at the time and place where such knowledge is produced. The combined knowledge is part of the subject, but this can also be used by teachers and students in their individual learning. See Fig. 1d.

Thus, the model should be based on active methodologies; this should encourage the creation and sharing of knowledge by students and teachers. And it should allow the combination of knowledge of students and teachers in real time.

In previous research, there have been various models that individually give support to these identified characteristics. The RT-CICLO model [16] supports the features 
defined in Fig. 1a, b and c and the ACCI 3.0 model [17] supports those described in Fig. 1d. These models are explained below.

\subsection{Model RT-CYCLE for Strong Socialization, Creation and Sharing of Knowledge by Students and Teachers}

It is based on the fact that students participate actively in the learning process. It would be enough to apply a methodology considered as active, such as Flipped Classroom [18], Project Based Learning (PBL) [19], Gamification [20], or Game Based Learning (GBL) [21].

All of these methodologies have some characteristic processes and procedures that should be applied during the development of the subject. In this work we have used our own model called RT-CICLO (Fig. 2), this uses the basic characteristics of different theories, models and methods of active learning. This model is characterized because it is very simple and can be used punctually or continuously in the development of a subject. For example, you can use it during a $10 \mathrm{~min}$ master class or continue in a set of class.

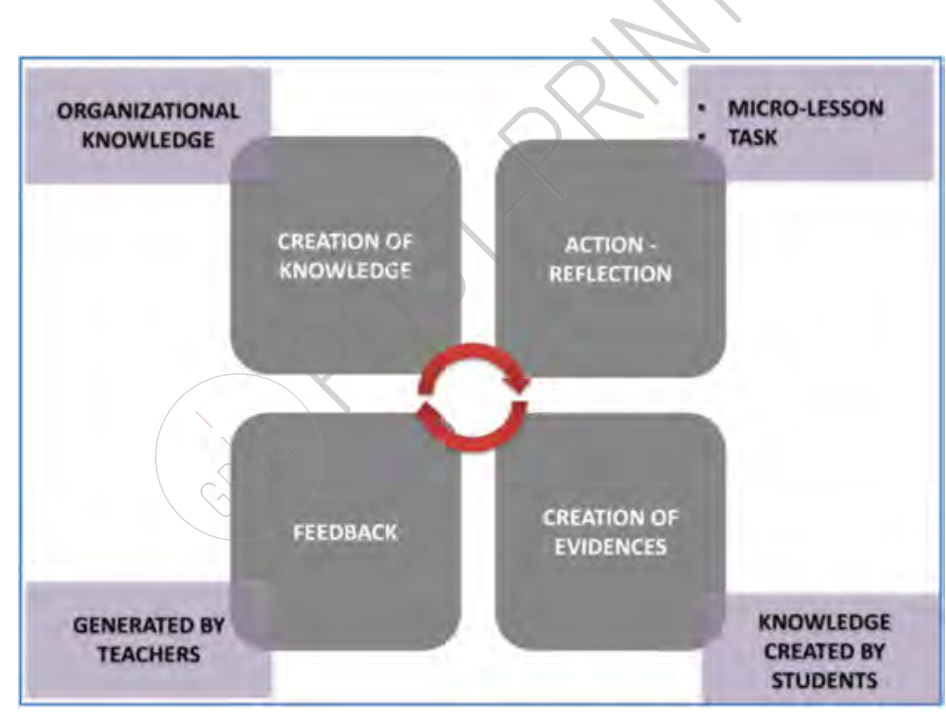

Fig. 2. Model RT-CICLO

The model, described in Fig. 2, is based on five actions grouped into four phases, as follows:

- Phase 1. Action-reflection. This set of actions aims to provide a minimum but necessary knowledge (micro-lesson) that guides students in the performance of a specific task. This task is a micro individual or group work, where you must make a reflection and decision making. 
- Phase 2. Creation of evidence. The evidence is the result of the task, which may be right or wrong. The result must be make explicit and shared online. If the result has been correct, it is considered as evidence that the student has acquired positive learning. If the result has been incorrect, it has also acquired learning because one learns from your own mistakes (as long as they are corrected).

- Phase 3 - Feedback. In this phase the teacher selects results that are correct and others that are incorrect. The objective is to improve the learning produced in the previous phase. When feedback is given on a correct result, all students learn from it. The same happens when you make a feedback of the wrong result, all the students will learn, because you are showing an error and how to correct it. This phase gives knowledge to all the students and the learning will improve greater variety of correct or incorrect results. The feedback can be done by the teachers or the students. In any case, the faculty must coordinate the process, selecting the results with which they will work and managing the time.

- Phase 4 - Knowledge creation. This phase is based on the students and teachers make explicit the knowledge acquired in the previous phases and sharing it.

\subsection{Model ACCI 3.0 to Combine Knowledge Generated by Teachers and Students in Real Time}

This model ACCI 3.0 (Active Cooperative Collective Intelligence) consists of two parts. On the one hand, the functional theoretical model (Fig. 3) and, on the other hand, software developed to support this functional theoretical model (Fig. 4). Initially, the model was based on a social network [22], but due to the difficulty of finding content within a social network [23], a self-development was carried out. That development consisted in the programming of a plugin [24] for the content manager WordPress.

The components of the functional theoretical model of Fig. 3 are described below:

- Ontology (Fig. 3a). Set of labels grouped into categories that allow to identify (know the different types), classify (sort them by various criteria) and organize (the form that is displayed to users) the explicit knowledge generated.

- Repository (Fig. 3b). Physically stores all explicit knowledge. The repository is composed of explicit knowledge together with the elements of ontology.

- Inferences between the elements of the ontology (Fig. 3c). The inference makes it possible to interact between the different elements of the ontology and to relate any element of the ontology according to the interest of each user and the action that it wishes to carry out.

- Semantic search (Fig. 3d). Use the inferences between the elements of the ontology to define a logical expression that has to meet the organizational knowledge sought. You can do a search by text, but also indicating that it must meet a certain relationship between the elements of the ontology. For example, you can specify that you want to search "integration polynomials" and that it meets the characteristics "that serve to understand the concept" and that also "show an example".

- Meta-information (Fig. 3e). Meta-information is added to each of explicit knowledge; the meta-information is the relationship of that knowledge with the ontology. For example, using the previous example, the knowledge "interpolation polynomials" can be associated with the meta-information "explain concept", "example", "2018/19 course", "Mines degree" and "vector data structure". 


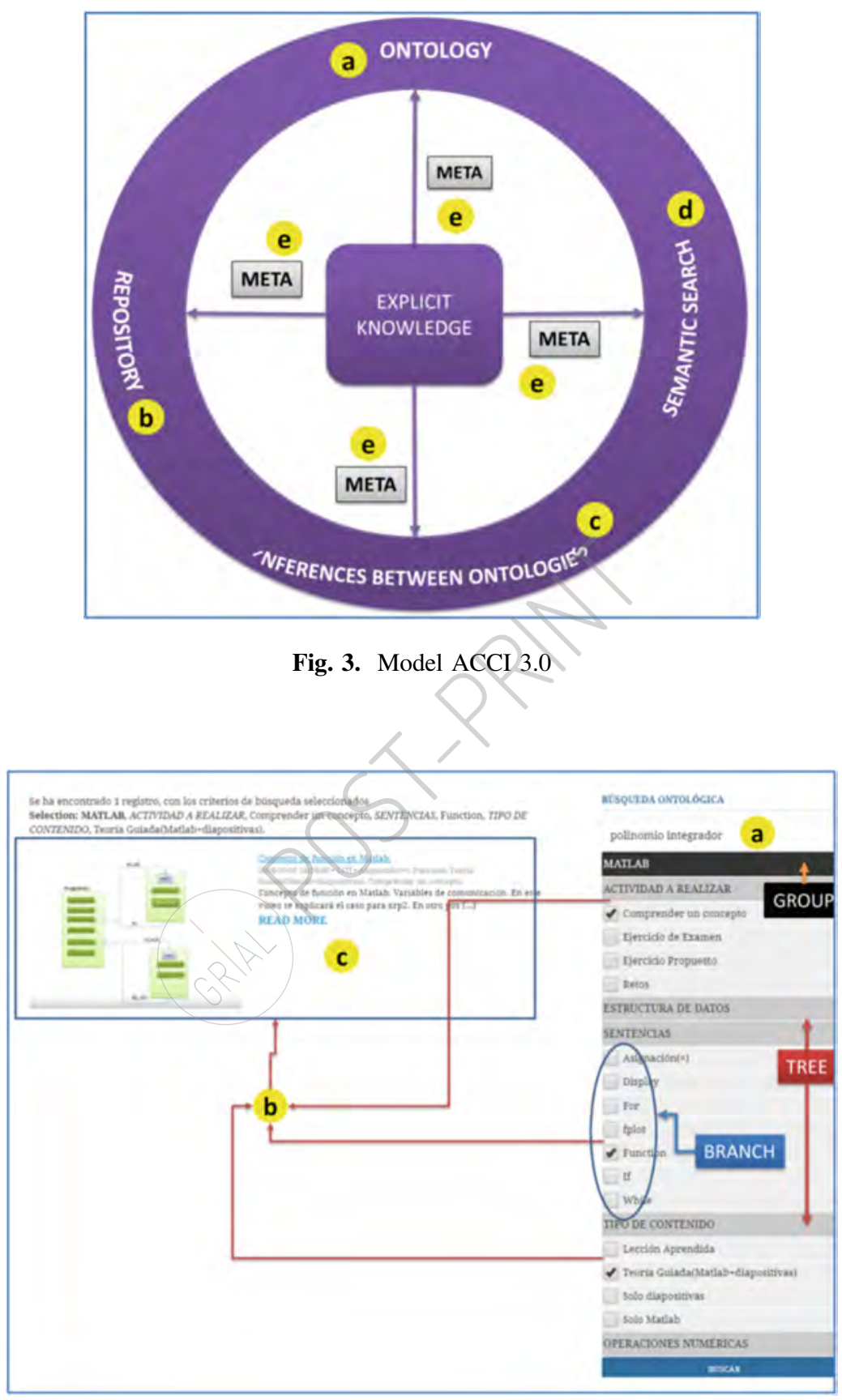

Fig. 4. Semantic search through inferences between the elements of the ontology 
The software developed for this model allows all the functionalities of the theoretical model. Figure 4 shows how several of these functionalities are performed. Figure 4a shows an example of the ontology of Fig. 3a. The ontology is composed of the following hierarchical elements:

- Group. Represents the context of the application, the figure is the Matlab application used in programming laboratories. A group can have " $n$ " elements "Tree".

- Tree. It represents a classification of explicit knowledge. Figure 4a shows five classifications: "Activity to be carried out" (academic action for which knowledge is to be used), "Data structure", "Sentences" used in the different programs, "Type of content" and "Numerical operations". Each explicit knowledge can belong to one to several Tree, and each Tree includes a set of metadata.

- Branch. They are the different metadata that is associated with each explicit knowledge. For example, the Tree "Activity to be performed" has the branches "Understand a concept", "Exam exercise", "Proposed exercise" and "Challenge" to be performed.

Figure $4 \mathrm{~b}$ indicates a semantic search through inferences between the elements of the ontology. In this case, search for the text "Interpolating polynomial". The knowledge has to serve to "Understand a concept" (about the "interpolating polynomial"), that knowledge uses a sentence "Function" and that the content type is "Guided theory (Matlab + slides)", that is, a tutorial. Figure $4 c$ shows the resources found, which meet the inference and, therefore, serve to their purpose.

The application of this combination of models allows transforming individual knowledge into corporate knowledge. In previous research, these models were used to generate organizational knowledge about university educational innovation based on good practices carried out in different subjects of different universities [25-27].

In this work, we use the combination of models in a specific subject, whose description is indicated in the next section on the research context. Likewise, identify the actions and tools that have allowed to create organizational knowledge, the types of knowledge that have been generated and the perception of the students to use each class, which will be presented in the results section.

\section{Research Context}

The research was conducted in the "Computer Science and Programming" subject, which corresponded to the first academic year of the Energy Engineering and Mine Engineering degrees. The model was applied during the academic course 2018-19, to create organizational knowledge during the laboratory sessions of Matlab programming from the Energy Engineering degree in the first semester. Each laboratory was organized into 12 sessions lasting $2 \mathrm{~h}$ each. In each session, the combination of theoretical models expressed in the previous phase was applied. This combination was implemented in the 2018-2019 academic year. The organizational knowledge, already created in the first semester, was applied to one laboratory group during the second semester of 2018-2019 of the Mine Engineering degree, to measure the perception of the usefulness of the organizational learning elements used. 
The RT-CICLO model was used in two ways:

- RT-CICLO Proposed exercise. Around the realization of a proposed exercise, phases 1, 2 and 4 were carried out in a virtual way (outside the classroom) and phase 3 in person in the classroom. Each cycle lasted a week.

- RT-CICLO Challenge. Through the challenges (micro-exercises) carried out in the classroom. All the phases are carried out face-to-face in the same session. The average duration was $30 \mathrm{~min}$. In each session, one cycle was carried out at least.

The ACCI 3.0 model and the software to manage the knowledge created, was applied continuously during all the cycles. In real time, the knowledge produced by the students and the teaching staff was introduced through the software. Based on this added knowledge, the results that we were obtained are: activities that generate organizational knowledge and types of corporate contents created during those actions.

During the second semester of the same course, the organizational knowledge developed was used in the "Computer Science and Programming" subject of the Energy Engineering degree. A laboratory group of that subject completed a survey on "Perception of usefulness for learning the different types of elements of organizational learning". The qualitative results obtained in this work are presented in the next section.

\section{Results}

The results of this work have been obtained in the following two scenarios within the experience:

- In scenario 1 the students, from the laboratories of the first semester, contributed to create the organizational knowledge (total of 66 students). In this scenario, two types of indicators have been identified that make it possible to assess organizational learning: the first indicator consists of identifying in what activities the students have generated organizational knowledge, and the second indicator is based on the types of organizational knowledge created.

- In scenario 2 the students, of the second semester, used the organizational knowledge of scenario 1 and assessed their perception of the usefulness of this knowledge in their learning.

\subsection{Scenario 1: Identification of Actions that Generate Organizational Knowledge and the Type of Knowledge}

The active methodology based on RT-CICLO got the students involved in the learning process, generating different types of knowledge through different actions. First, the actions are identified, and then the typology of knowledge created during the various actions is presented.

Identification of Actions. Actions have been of two types: voluntary (in these students have created knowledge spontaneously and unplanned) and involuntary (in these students have created knowledge from the realization of processes planned by the teachers). 
Likewise, the contexts where this knowledge has been generated have been taken into account, distinguishing two meanings: during the classroom sessions and outside of them (e.g., at home). Taking into account the type of action and the context where it occurred, the shares are distributed as shown in Table 1.

Table 1. Identification of actions that can originate organizational knowledge

\begin{tabular}{l|l|l}
\hline $\begin{array}{l}\text { Actions that originate } \\
\text { organizational knowledge }\end{array}$ & Inside the classroom(1) & Outside the classroom(2) \\
\hline Voluntary (A) & $A 1$ - Doubts and answers & $A 2$ - Tutorials \\
\hline Involuntary (B) & $\begin{array}{l}\text { B1 - RT-CICLO Challenges } \\
B 1-\text { Mistakes }\end{array}$ & $\begin{array}{l}\text { B2 - RT-CICLO proposed } \\
\text { exercises }\end{array}$ \\
\hline
\end{tabular}

The first column of Table 1 represents the type of action carried out by the students. Voluntary actions (second row) are those that are generated spontaneously by students. The involuntary ones (third row) are those created by the application of the model or by the results of mandatory actions (for example, doing an exercise in class).

The second column includes the voluntary and involuntary actions that arise during the teaching of a face-to-face class in the classroom. These actions generate organizational knowledge in real time and synchronously. The third column includes voluntary and involuntary actions that arise outside the classroom. The organizational knowledge created by these actions is carried out asynchronously and for a determined period.

The actions that produced organizational knowledge were the following, to facilitate the placement are assigned a letter A (Voluntary), B (Involuntary) and a number (1) Inside the classroom and (2) Outside the classroom.

A1. The two most common actions were the doubts expressed by the students during the face-to-face sessions and the responses of the students themselves or of the teachers.

$A 2$. The most common action was attendance at face-to-face tutorials in the office of the faculty, where the students also raise questions and answers are given only by the faculty.

B1. Two common actions stand out:

- The application of RT-CICLO during a face-to-face session and which has been called RT-CICLO Challenge.

- The exposure of the common mistakes that students often make in class.

B2. The usual activity is the application of the RT-CICLO model in proposed exercises.

Types of Organizational Knowledge Generated from the Previous Actions. The different types of knowledge originated are described below, associating this with the actions in which it was created (A1, A2, B1 or B2) and these are:

- Collaborative doubts. 
- Orientations.

- Mistakes.

- Lesson learned.

Collaborative Doubts (Origin A1). Teachers must make explicit in the classroom the knowledge that is being taught. About this explicit knowledge the student expresses doubts, makes comments and even answers some doubt. This resource is created in real time. Figure 5 shows a concept explained in the classroom (Fig. 5a) and the comments made by the students, together with the questions and answers shown in Fig. $5 \mathrm{~b}$.

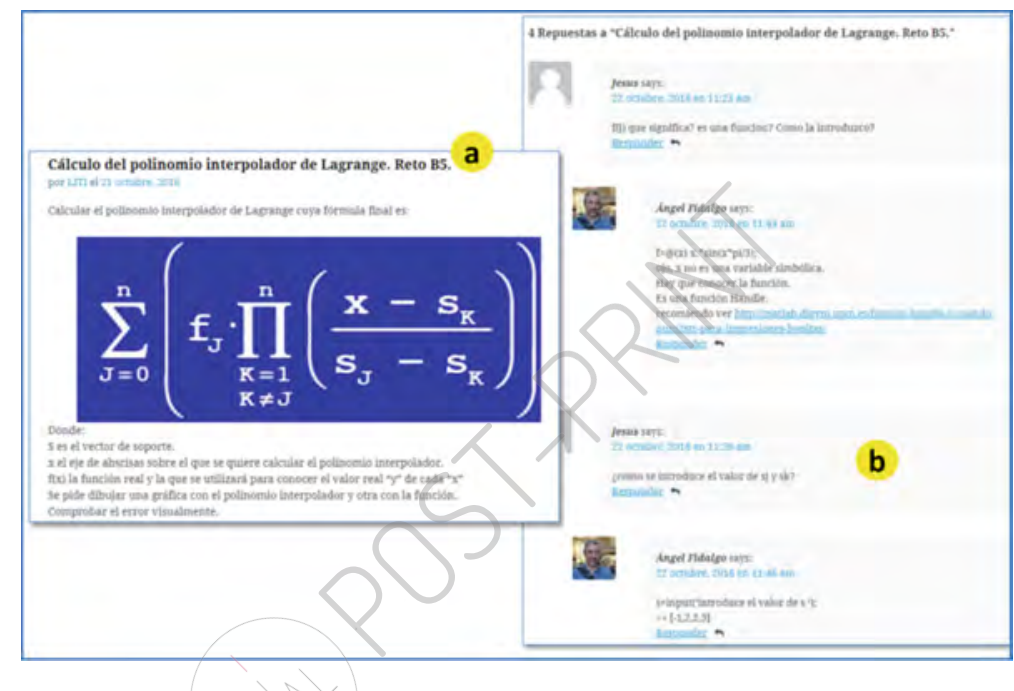

Fig. 5. Organizational knowledge elaborated by uniting the concept with the doubts and answers that it has generated

Orientations (Origin A2). These are prepared synchronously in the last laboratory sessions. A compendium of the concepts that have had to be explained more often in tutorials is made. It consists of collecting information from the tutorials carried out by the students. Two types of knowledge have been generated: those related to the technical part and those that affect the decision-making part (strategy).

Errors (Origin B1). A characteristic example is based on the mistakes that students make during the development of a class exercise. The faculty identifies these, groups these and explains both the error and the way of not committing it. Figure 6 shows a characteristic error to which a code has been assigned, in this case ER \# 2. It describes the error, the cause and the way to solve (Fig. 6a) and is accompanied by a visual image that lets us know that the error has been corrected (Fig. 6b). 


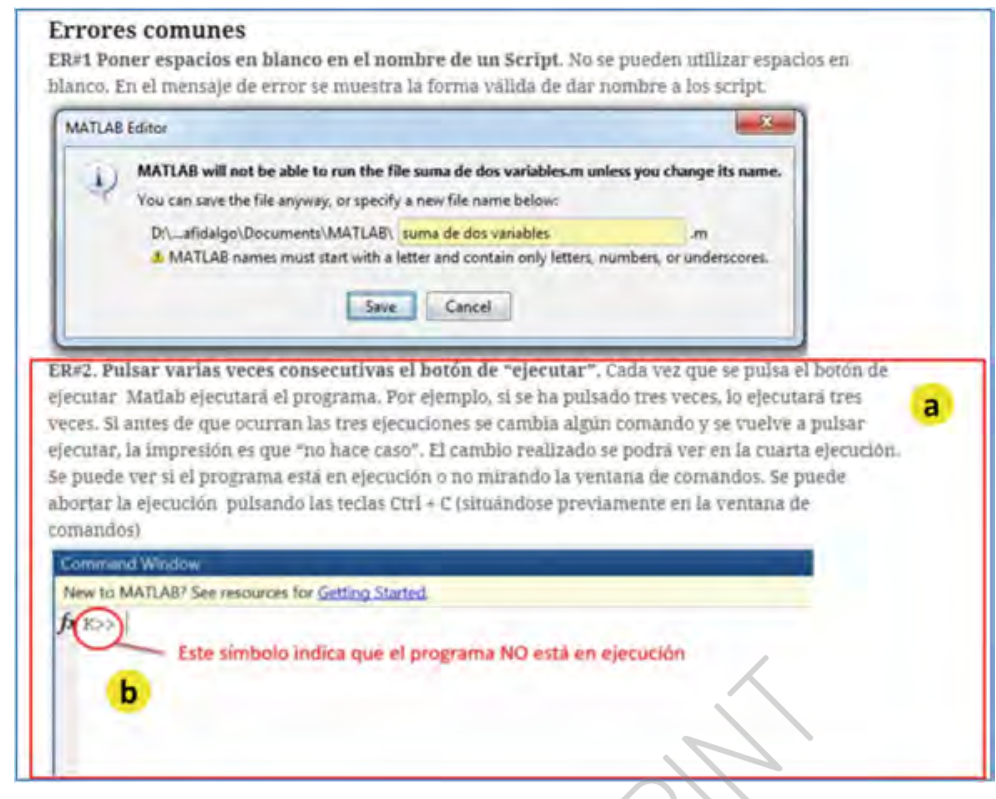

Fig. 6. Organizational knowledge elaborated from the usual mistakes

Lesson Learned. Knowledge Generated by RT-CICLO (Origin B1 and B2). This resource is generated by joining the result of all the RT-CICLO application phases. It combines:

- The proposed exercise or challenge.

- A selection of correct and incorrect results, together with that feedback.

- Comments added by the teachers and students about their experience during the realization (if it was easy or complicated, tips, etc.).

\subsection{Scenario 2. Perception of the Students About the Different Elements of Organizational Learning}

This test was carried out through a survey of students of the second semester in the 2018-19 course of "Computer Science and Programming" subject. These students study the degree of Energy Engineering and have used the organizational learning generated in the previous semester, with students of the degree in Mine Engineering. The test was completed once the first lab session ended, where they had the opportunity to use organizational learning.

A survey with five questions was carried out. They were asked about the perception of the usefulness (scale Likert 1 - low to 5 - high), for their personal learning, of the following types of organizational knowledge:

- Q1 - Collaborative doubts.

- Q2 - Technical guidance.

- Q3 - Strategic orientation. 
- Q4 - Common mistakes.

- Q5 - Lesson learned.

Of a total of 33 people enrolled in the laboratory, the survey was filled out by 27 people ( $82 \%$ of those enrolled). The program R, library R-Commander has been used for the calculations.

The results of the survey are shown in Table 2, with the identifier of the question (Qi), the mean and the standard deviation SD of the answers.

Table 2. Results of the satisfaction survey

\begin{tabular}{l|l|l}
\hline Question & Mean & SD \\
\hline Q1 & 4.84 & 0.36 \\
\hline Q2 & 4.48 & 0.75 \\
\hline Q3 & 4.15 & 0.86 \\
\hline Q4 & 4.63 & 0.69 \\
\hline Q5 & 4.63 & 0.49
\end{tabular}

\section{Conclusions}

The knowledge generated by the students during the learning process in combination with the contributions of the teachers, produces organizational knowledge and for learning purposes, we can affirm that the subject has increased their knowledge, that is, in this case, the subject "has learned".

Organizational knowledge can be obtained through a series of actions by students. The actions identified in this work are:

- The doubts and answers regarding a specific topic.

- The mistakes made when performing exercises.

- Face-To-Face tutoring.

- The activities are implicit in the RT-CICLO process.

Organizational knowledge can be generated from each action. Depending on each action knowledge has been determined by the following types:

- Cooperative doubts. From the actions of the doubts and answers. Organizational knowledge consists in uniting the concept with which one works and the doubts and answers that have originated in its explanation or application.

- Common mistakes. Compilation of the mistakes that students make when performing exercises.

- Technical guidance and decision making. Elaborated from the conceptual, technical and decision-making deficiencies that the students show in face-to-face tutoring.

- Learned lessons. Combination of knowledge generated by each phase of the RTCICLO model.

All the types of elements described constitute organizational knowledge, and its improvement is associated with increased learning. 
Organizational knowledge can also be used to promote individual student learning. The perception survey indicates that for all types of organizational knowledge students have a very high perception of their usefulness. All means exceed 4 points out of 5 , with standard deviations less than 1.

It is shown that the combination of RT-CICLO models, as an active method, and ACCI 3.0, to transform individual and organizational knowledge, can be applied to produce that knowledge and organizational learning in a subject.

In this work, organizational knowledge has been generated for the first time in a subject. In future work that knowledge acquired in the subject will be applied with students of a new subject, measuring the impact on the learning of the subject itself (measuring the increase in knowledge) and the effect on the students' own learning (measuring the actions carried out to generate new knowledge, the development of learning and the academic performance of it).

Acknowledgments. This work has been partially funded by the Spanish Government Ministry of Economy and Competitiveness throughout the DEFINES project (Ref. TIN2016-80172-R) and the Educational Innovation Service of the Technical University of Madrid (project Ref IE1819.0602). The authors would like to thank the research groups GIDTIC (http://gidtic.com), GRIAL (http://grial.usal.es) and LITI (http://www.liti.es) for their support.

\section{References}

1. Nonaka, I.: A dynamic theory of organizational knowledge creation. Organ. Sci. 5, 14-37 (1994)

2. Nonaka, I., Takeuchi, H.: The Knowledge-Creating Company: How Japanese Companies Create the Dynamics of Innovation. Oxford University Press, Oxford (1995)

3. Bloom, B.S., Engelhart, M.D., Furst, E.J., Hill, W.K., Krathwohl, D.: Taxonomy of educational objectives: the classification of educational goals. Handbook I: Cognitive domain. In: Taxonomy of Educational Objectives: The Classification of Educational Goals. Handbook I, pp. 201-207. David McKay Company, New York (1956)

4. Ausubel, D.P.: A cognitive theory of school learning. Psychol. Sch. 6, 331-335 (1969)

5. Piaget, J.: Part I: Cognitive development in children: Piaget development and learning. J. Res. Sci. Teach. 2, 176-186 (1964)

6. Kolb, D.A.: Experiential Learning: Experience as the Source of Learning and Development. Prentice-Hall Inc, Englewood Cliffs (1984)

7. Fidalgo-Blanco, Á., Sein-Echaluce, M.L., García-Peñalvo, F.J.: APFT: active peer-based flip teaching. In: Proceedings of the 5th International Conference on Technological Ecosystems for Enhancing Multiculturality, TEEM 2017, Article No. 83. ACM, New York (2017)

8. García-Peñalvo, F.J., Alarcón, H., Domínguez, Á.: Active learning experiences in engineering education. Int. J. Eng. Educ. 35, 305-309 (2019)

9. Dewey, J.: Democracy and Education: An Introduction to the Philosophy of Education. The Macmillan Company, New York (1916)

10. Dewey, J.: Experience and Nature. George Allen \& UNWIN, LTD, London (1929)

11. Bonwell, C.C., Eison, J.A.: Active learning: creating excitement in the classroom. School of Education and Human Development, George Washington University (1991) 
12. Sein-Echaluce, M.L., Fidalgo-Blanco, A., García-Peñalvo, F.J.: Students' knowledge sharing to improve learning in academic engineering courses. Int. J. Eng. Educ. (IJEE) 32, 1024-1035 (2016)

13. Honey and Mumford-University of Leicester. https://www2.le.ac.uk/departments/ doctoralcollege/training/eresources/teaching/theories/honey-mumford. Accessed $19 \mathrm{Feb}$ 2019

14. Paavola, S., Hakkarainen, K.: The knowledge creation metaphor - an emergent epistemological approach to learning. Sci. Educ. 14, 535-557 (2005)

15. Chickering, A.W., Gamson, Z.F.: News Seven Principles For Good Practice in Undergraduate Education A Focus for Improvement. Washingt. Cent. News. (1987)

16. García-Peñalvo, F.J., Fidalgo-Blanco, A., Sein-Echaluce, M.L., Sánchez-Canales, M.: Active Peer-based Flip Teaching: An active methodology based on RT-CICLO. IGI Global (2019, in press)

17. Sein-Echaluce, M.L., Fidalgo-Blanco, A., García-Peñalvo, F.J.: Technological ecosystems and ontologies for an educational model based on Web 3.0. Univers. Access Inf. Soc. (2019, in press)

18. Khailova, L.: Flipping library information literacy sessions to maximize student active learning: toward articulating effective design and implementâtion principles. Ref. User Serv. Q. 56(3), 150 (2017)

19. Vidoni, M., Montagna, J.M., Vecchietti, A.: Project and team-based strategies for teaching software architecture*. Int. J. Eng. Educ. 34, 1701-1708 (2018)

20. Rodríguez, M., Díaz, I., Gonzalez, E.J., González-Miquel, M.: Motivational active learning: an integrated approach to teaching and learning process control. Educ. Chem. Eng. 24, 7-12 (2018)

21. Torres-Toukoumidis, Á., Ramirez-Montoya, M.S., Romero-Rodriguez, L.M.: Valoración y evaluación de los Aprendizajes Basados en Juegos (GBL) en contextos e-learning. Educ. Knowl. Soc. 19(4), 109-128 (2019)

22. Fidalgo-Blanco, Á., Sein-Echaluce, M.L., García-Peñalvo, F.J.: Micro flip teaching with collective intelligence. In: Zaphiris, P., Ioannou, A. (eds.) LCT 2018. LNCS, vol. 10924, pp. 400-415. Springer, Cham (2018). https://doi.org/10.1007/978-3-319-91743-6_30

23. Santoveña-Casal, S., Bernal-Bravo, C.: Exploring the influence of the teacher: Social participation on Twitter and academic perception. Comunicar: Media Educ. Res. J. 27, 7584 (2019)

24. Fidalgo-Blanco, Á., Sánchez-Canales, M., Sein-Echaluce, M.L., García-Peñalvo, F.J.: Ontological search for academic resources. In: Proceedings of the Sixth International Conference on Technological Ecosystems for Enhancing Multiculturality - TEEM 2018, pp. 788-793. ACM Press, New York (2018)

25. Fidalgo-Blanco, A., Sein-Echaluce, M.L., García-Peñalvo, F.: Epistemological and ontological spirals: From individual experience in educational innovation to the organisational knowledge in the university sector. Program 49(3), 266-288 (2015)

26. Fidalgo-Blanco, Á., Sein-Echaluce, M.L., García-Peñalvo, F.J.: Knowledge spirals in higher education teaching innovation. Int. J. Knowl. Manag. 10(4), 16-37 (2014)

27. Sein-Echaluce, M.L., Abadía-Valle, A.R., Bueno-García, C., Fidalgo-Blanco, A.: Interaction of knowledge spirals to create ontologies for an institutional repository of educational innovation best practices. Int. J. Hum. Cap. Inf. Technol. Prof. 8(2), 72-92 (2017) 